\title{
Communication in a Leadership Team for Systemic Change in a School District
}

\author{
Zengguan Chen \\ Charles M. Reigeluth \\ Indiana University, United States
}

\begin{abstract}
Fundamental change, or systemic transformation, in public school systems is increasingly recognized as essential for best meeting all students' needs in a digital, information-based society. The success of this kind of change depends to a large extent on the effectiveness of a district-wide Leadership Team (LT), which in turn depends on the communication practices of that team. This study describes the communication practices of the LT in a district-wide systemic transformation, focusing on the members' values and beliefs about communication within the team, communication problems, communication channels, and communication sources. The purpose of the study was to improve the guidance offered by the School System Transformation (SST) protocol, a knowledge-base about the systemic transformation process, by identifying preventive measures that could reduce communication problems in a LT. Based on the findings, suggestions are made to improve several of the 18 continuous processes in the SST Protocol, namely sustain motivation, develop and maintain appropriate leadership, develop group-process and team-building skills, establish team spirit, engage in reflection, communicate with stakeholders, and foster organizational learning.
\end{abstract}

Keywords: Systemic transformation; Change process; Leadership team; Communication

\section{Introduction}

\section{Why Systemic Transformation Is Important?}

Over the $20^{\text {th }}$ century, various school reform efforts were made to improve existing educational systems to better serve communities (Schlechty, 1990). However, experience has indicated that school reform as piecemeal change is not enough to improve the overall system, whether the system is a classroom, a school, a school-within-a-school, or a school district (Reigeluth, 1999). A systemic transformation, which must include all aspects of the system, should be a true transformation. According to Reigeluth and Joseph (2001), a systemic transformation approach in $\mathrm{K}-12$ settings could bring significant improvements to the educational experience of students and their families, school employees, and the entire community.

As we enter deeper into the Information Age, our society's educational needs and problems are changing dramatically. Societal systems, jobs, and even personal lives are becoming more 
complex. This overall background sets new requirements for our educational systems. The typical response in school districts to new educational requirements is a piecemeal, "fix-the-broken-part" approach to change. These changes are made by schools to adjust to immediate challenges that arise during the normal course of schooling. What is seldom recognized is that dramatic changes in educational needs require changes in the fundamental structure and organization of school systems. According to Reigeluth (1997), our current educational system was designed more for sorting students than for learning, which was appropriate in the Industrial Age in which manual labor was predominant. However, the Information Age, with its predominance of knowledge work and global competition, has dramatically changed that, making learning a much higher priority than sorting. In the Information-Age society we need to educate more children to their potential. Given that students learn at different rates, when time is held constant, learning varies. To maximize learning, time must become flexible, and student progress must be based on a predetermined level of mastery, not on a predetermined amount of time. This change in the use of time requires fundamental changes in the use of talent (teachers and students) and technology (Schlechty, 2002). It requires fundamental changes from standardization to customization, from control to empowerment, from compliance to initiative, and from uniformity to diversity (Reigeluth, 1999). We refer to such fundamental change as paradigm change or transformational change.

Jenlink et al. (1998) define transformational change as an approach that recognizes the "interrelationships and interdependencies among the parts of the educational system, with the consequence that desired changes in one part the system must be accompanied by changes in other parts that are necessary to support those desired changes" (p. 219). It also recognizes the "interrelationships and interdependencies between the educational system and its community, including parents, employers, social service agencies and much more, with the consequences that all those stakeholders are given active ownership over the change effort" (p. 219).

\section{Guidance for the Systemic Transformation Process}

In the United States, a few school- and district-wide systemic transformation efforts have been implemented. Several design theories have been developed to guide systemic transformation efforts. One big category of these design theories is guidance primarily about what the school system should be like, not what the systemic transformation process should be like. These included two nationally recognized educational change methods, the Coalition of Essential Schools (CES) and Success for All - Roots \& Wings (SFA). CES (Sizer, 1984; 2002) is a system that promotes ten common and eight organizational principles as the foundation of their philosophy of schooling to restructure secondary schools. SFA (Slavin \& Madden, 2001; Stringfield, Ross \& Smith, 1996) is a school-wide change model with an underlying principle that promises "every child" will be successful in learning to read through their curriculum.

On the other hand, theories guiding the school system transformation process include the School Development Program (SDP), Knowledge Work Supervision ${ }^{\circledR}$ (KWS), the Guidance System for Transforming Education (GSTE), and Step-Up-To-Excellence (SUTE). SDP (Comer, Haynes, Joyner \& Ben-Avie, 1996) is a model that advocates on behalf of parents and families to have a central role in the transformation process for the education of their children. KWS (Duffy, Rogerson \& Blick, 
2000 ) is a methodology that assists the redesign of an entire school district from an innovative point of view by recognizing three fundamental principles: (a) understanding how systems change, (b) working with individuals as well as with groups, and (c) developing necessary attitudes and skills of those facilitating the change. The GSTE (Jenlink, Reigeluth, Carr, \& Nelson, 1996; 1998) is a guidance model to facilitate systemic transformation in K-12 school districts. Duffy also developed KWS into a larger framework to guide transformational change in school districts, which is called Step-Up-To- Excellence (SUTE). GSTE and SUTE were later blended into a new hybrid methodology, which is called the School System Transformation (SST) Protocol (Duffy \& Reigeluth, 2008). It has some sequential elements and some elements that need to be addressed continuously throughout the transformation process. The elements fall into five phases: prepare, envision, transform, sustain, and evaluate. Each step in the protocol is not in a lock-step sequence but should be perceived as a set of flowing activities that converge, diverge, and backflow from time to time. Each phase has several steps, and each step has multiple tasks and activities.

One of the phases in the SST Protocol addresses the process of forming and participating in a Leadership Team (LT), which could either promote the success or ensure the failure of a districtwide transformation effort, and thus is the focus of this study. The performance, contribution, and impact of a LT could be strongly influenced by the efficiency of communication among team members. The purpose of this study was to improve the guidance offered by the SST protocol by prescribing preventive measures that could reduce communication deficiencies in a LT.

\section{Communication Theory Related to Systemic Transformation}

The traditional definition of communication is the exchange of information, ideas, and feelings in order to get a message across (Mclntire \& Fessenden, 1994). There are various types of communication: intrapersonal, interpersonal, public, mediated, organizational, intercultural, and mass communication (Fiordo, 1990). Intrapersonal communication takes place within each of us as we talk to ourselves; interpersonal communication describes communication among participants who are dependent upon one another and have a shared history; public communication refers to the sending of messages to an audience; mediated communication pertains to the use of various technologies to mediate the sending and receiving of meaning and messages; organizational communication refers to messages transacted within, from, and to an organization; intercultural communication applies to sending and receiving messages among organizations and individuals from different cultures and societies; and mass communication is about how individuals and entities relay information through mass media to large segments of the population at the same time.

Considering the above categorization of communication and the purpose of this study being closely associated with a LT, our attention will only be given to interpersonal, public, and mediated communications because they are directly related to communication skills the team members are expected to acquire, communication channels and sources desired by the team, and how to improve communication deficiencies among different stakeholder groups. In the later phases of the research, organizational communication will be touched upon, since the findings from the analysis of the current data collected strongly suggest a close relationship between internal LT communications and the LT's communication with stakeholder group members outside the team. 
Intrapersonal, intercultural and mass communication will be skipped in this study because it specifically focuses on communication within a LT.

Although issues related to leadership communication have been well researched in both school and corporate settings, researchers usually tend to focus on communication strategies or skills leaders or executives are supposed to have in order to guide, direct, motivate, and inspire people through effective communication. For example, Barrett (2008) summarized and proposed several leadership communication frameworks, arguing that leadership communication consists of layered, expanding skills, from core strategy development and effective writing and speaking, to the use of these skills in more complex situations. However, those frameworks and skills are not relevant to a $\mathrm{LT}$, because the it consists of different stakeholders in the school district, including administrators, teachers, parents, community members, support staff, school board members, and ministerial staff, who all have an equal voice on the team.

The composition of a LT generally reflects the application of the stakeholder participation concept. Stakeholder participation has been defined as "a process whereby stakeholders - those with rights (and therefore responsibilities) and/or interests - play an active role in decision-making and in the consequent activities which affect them" (SDD, 1995, p.5). Stakeholder participation in the decision-making of educational systems can potentially improve their design and implementation by improving ownership, building consensus, helping to reach disadvantaged groups, mobilizing additional resources, and building institutional capacity (Colletta \& Perkins, 2007).

A LT formed under the guidance of the SST protocol to fulfill the mission of guiding the systemic transformation process in a school district is a significant concept for today's educational settings. An industrial-age mindset of decision-making has prescribed change in education for many years through a top-down decision-making structure that functions with little input from its stakeholders. The introduction of decision-making teams (comprised of diverse stakeholders in the organization) into the leadership of organizations has revolutionized the way these organizations function and produce (Duffy \& Reigeluth, 2008).

Senge (1990) argues that a learning team within an organization has the capacity to think together and dialogue with the purpose of learning together. He states that team learning is the process of aligning and developing the capacity of a team to create the results its members truly desire. Duffy and colleagues (2000) proposed a systemic transformation process to transform school systems into high-performing organizations of learners through team-based design work. Some advantages of using teams in systemic transformation efforts include: (a) teams increase participation and collaboration, which could increase motivation, job satisfaction, and commitment; (b) teams dissolve hierarchies within institutions, creating opportunities for communication and collaboration; (c) teams promote conditions for creation and diffusion of knowledge; and (d) those who are closest to the work understand best how to improve it (Duffy et al., 2000). It can be observed that communication permeates all these factors in order for them to be successfully achieved. However, little is known about the specific communication skills needed by each member of a LT for systemic transformation, in order for the team to be most effective. Also, little is known about the influence of culture and climate on a LT's communications. Finally, little is known about ways that communication channels and sources can affect team communications. This study attempts to fill these gaps in knowledge. 
In addition to communication skills that each member is required to possess, this study seeks to investigate whether or not the team culture and climate are conducive to communication and whether or not communication channels and sources are supportive of team communication. These issues were developed into research questions to examine the current status of internal communications within a LT.

\section{Research Questions}

The research questions are:

1. What are the communication patterns of the LT (who do members share ideas with and how often)? What characteristics of communication exist within the team?

2. What are team members' values, beliefs, and perceptions about their team communication?

3. What are the means and sources of communication within the team?

4. What are the communication deficiencies and how can they be improved?

\section{Methods}

This research study employed a formative research methodology, which follows a case study methodological approach in qualitative research (Reigeluth \& Frick, 1999). According to Reigeluth and Frick (1999), formative research asks three basic questions: (1) What is working? (2) What needs to be improved? and (3) How can it be improved? Formative research is a kind of developmental research or action research that is intended to improve design theory for designing instructional practices or processes (Reigeluth \& Frick, 1999). This methodology is useful in identifying what worked for communication at LT meetings and how communication could have been improved, indicating possible additions to the SST Protocol to improve communication at LT meetings.

Formative research classifies case studies as either designed or naturalistic cases. According to Reigeluth and Frick (1999), formative research is a designed case when a theory/model is instantiated and then formatively evaluated. In contrast, formative research is a naturalistic case when the case selected was not specifically designed according to the theory but serves the same goals and contexts (Pascoe, 2008). This study used a naturalistic case. According to Reigeluth and Frick (1999), in naturalistic cases the formative evaluation of the instance can be done in vivo (during its occurrence) or post facto (after its occurrence). This research study was a post facto naturalistic case because it was studied after the case had already taken place.

A naturalistic study is usually conducted based on the following procedure: (1) Select an existing theory; (2) Select a case; (3) Collect and analyze formative data on the case; and (4) Offer tentative revisions for the theory (Reigeluth \& Frick, 1999). With this procedure serving as the basic framework of the current study, the researcher aimed at revising the current SST theory relevant to communications in a LT. 


\section{The Case}

The school district selected for this study was the Metropolitan School District of Decatur Township (MSDDT) in Indianapolis, Indiana, with an approximate population of 24,000. It was one of eleven public school corporations in Indianapolis' Marion County, and at the time of the study served approximately 5,500 students. MSDDT offered one centralized early childhood program, four elementary schools (grades 1-4), two intermediate schools (5-6), one middle school (7-8), and one central high school having five academies (9-12). At the time, students were served by almost 260 full-time teachers and more than 280 professional staff members. Approximately 90 percent of MSDDT students were considered white, and some 49 percent of the student population received free or reduced lunches and textbooks (Pascoe, 2008). In 2001, MSDDT and Indiana University established a partnership to enhance the educational opportunities offered to students, their families, and the community-at-large through a district-wide systemic transformation process using the SST Protocol.

\section{Leadership Team}

In the spring of 2001, a predecessor of the Leadership Team, named the Core Team, was formed. They met as a team to identify core values and ideas that could guide the MSDDT to improve its educational process and include all stakeholders in reaching consensus on the changes that could most benefit their students. This Core Team met almost every week until the end of the fall of 2002, at which point they expanded into the LT, though they continued to meet as a Facilitation Team for planning the LT meetings. In February 2003 the newly formed LT of about 25 people had a broad representation of MSDDT stakeholder leaders, including community members, to work together to design better learning experiences for students in this school district.

From mid-November 2003 through April 2004 a second phase of the LT took place. The LT was reconstituted and expanded, and devoted time to reviewing data gathered from stakeholders in the school system about the need for systemic transformation in their school district. Next, the LT developed a Framework of mission, vision, and ideal beliefs about education, developed in collaboration with community members, which became prominent throughout the MSDDT. At the time of this study, the LT had 40 members, including 11 administrators, 11 teachers, seven parents, four community members, two support staff, one school board member, one ministerial member, and three outside facilitators. The time period of the current study was October to December of 2008.

\section{Data Collection and Analysis}

In this study, observation, survey, focus-group/individual interviews, and documents were used as main techniques for data collection. Hand analysis was used as the analysis approach, and findings were validated through triangulation and member checking. 


\section{Observation}

Assuming a role of nonparticipant observer, the researchers observed LT meetings, which were held once a month. We attended meetings and observed discussions to further inform the development of the SST Protocol. Field notes about communication and types of information considered and used were produced during three two-hour meetings in October, November, and December of 2008. The field notes were used for identifying themes related to communication in the LT and for informing the survey questions and interview protocols developed later.

\section{Survey}

A short questionnaire with three questions was sent out to the entire LT to capture the characteristics of the team's communications and the members' individual perspectives on good communication and leadership skills. In order to get the most responses from the team members, the survey was made as short as possible. It was sent out via e-mail together with a participant information sheet, and participants were reminded to reply only to the first author to protect their confidentiality. The survey was sent out multiple times, and 12 out of 37 members (excluding the facilitators) filled out the survey. The 12 respondents included five administrators, four teachers, and three community members. In the sample, the proportions of each stakeholder group were representative of the whole team. However, one limitation is that the sample members were not randomly selected.

The three questions asked in the survey were:

1. Within the LT, name the people with whom you are most likely to share new ideas. What is the frequency you communicate with each other related to the LT issues? (the number of times per day or per week or per month)

2. Within the LT, what people would you be most likely to choose as the team leader if you were to work on a team project? Why?

3. If you were going on a vacation, name the members on the LT you would like to go with. Why them?

\section{Interviews}

Eight members of the team were interviewed by the first author. Three of them were teachers, three of them were community members, one person was on the school board, and one was a school principal. It is notable that in this sample, the administrator, support-staff, and ministerial groups were underrepresented, and community members were overrepresented. The generalizability of the study results is thus reduced. The years these eight members had been on the team ranged from one to seven. The community members included parents, a retired teacher, and a person from a university located in the same city as the MSDDT. All of them had been living in the township for more than fifteen years. 
Two focus groups were conducted by the first author - one with three teachers and the other with two community members - based on a semi-structured interview protocol. Each focus group lasted about 30 minutes. The questions asked about team members' values, beliefs, and perceptions on team communication, sources and channels of team communication, deficiencies in team communication, and the management of the LT.

Three one-on-one interviews were conducted by the first author with a principal, a community member, and a member from the school board, with each lasting about 40 minutes. The same semi-structured interview protocols were used, and open-ended questions were asked to allow maximal flexibility for participants' responses. The researcher took brief notes during the interviews, and all the interviews were audio-taped and transcribed.

\section{Documents}

Public documents, such as minutes from LT meetings, official memos, newsletters, notes, records, and physical and on-line archival materials were collected as sources to make sense of communication channels and patterns in the LT. Notes were taken about the documents, to record information from them. The documents were used to gain a sense of the context and language used and to trace the linkages of discourse related to key themes.

\section{Data Analysis}

All the notes and materials obtained were organized by type, participant, site, and combinations of these categories. Duplicate copies of all forms of data were kept. All the interviews and observational notes were transcribed. The data analysis was conducted using such activities as data reduction, data display, and conclusion drawing (Miles \& Huberman, 1984). Data reduction is "selecting, focusing, simplifying, abstracting, and transforming the 'raw' data...." (Miles \& Huberman, 1984, p. 21). Summary information was placed in a matrix that specified relevant situational characteristics and arrayed categories of data (Miles \& Huberman, 1984).

Guided by this process, the first author read the data, marked them by hand, divided them into parts, and created a database. To narrow the text data into a few themes, the coding process was to make sense of the whole data, divide them into text, label the segments with codes, examine codes for overlap and redundancy, and collapse these codes into broad themes. The first author scanned theory and methods literature for ideas that would help make sense of emerging themes and concepts. Analytic memos and theoretical notes with commentary about emerging themes, anomalies or inconsistencies, and relationships were created. Portrayals of each theme were written, and tables and charts were produced to represent the findings.

\section{Validating Findings}

The findings were validated through the strategies of triangulation and member-checking. As stated in the data collection section, the researchers triangulated among different data sources to 
enhance the accuracy of the study. With different types of data (observational field notes, interviews, notes on documents) and different methods of data collection (observation, interview, document analysis), the information was drawn from multiple sources, which enhanced the accuracy and credibility of the findings. The researcher also checked notes and transcriptions with participants in the study to determine and enhance credibility. When the findings were checked back to participants, they were asked via e-mail about the accuracy of the report, whether the description was complete and realistic, and if the interpretations were fair and representative. The report was sent to them when the study was finished.

\section{Results and Discussion}

The results are organized and discussed in relation to the research questions. They start with the characteristics of the LT's communication, communication skills admired by the team members, followed by the team members' values, beliefs, and perceptions about their team communication, the means and sources of communication within the team, and the communication deficiencies detected by the members.

\section{Team Nature and Communication Networks}

The researchers intended to capture the characteristics of the team's communication by asking questions examining who the members were that most team members would like to share ideas with. The answers given by 12 members revealed that five people from the administrator group and three from the teacher group were most frequently chosen as people to share ideas with. The responses also showed that people tended to choose others from the same stakeholder group as themselves. Although the result was not based on the responses from all the team members, it appears that communication based on hierarchical ranks still plays a role in the team. However, another explanation is that, since the LT only met monthly, the administrators were the ones with whom the team members met most often outside of the team meetings, or administrators were in charge of the meeting planning and management, including member recruitment, therefore they were more familiar to most of the members. It needs to be noted that none of the community members, parents, support staff or school board members were chosen, which means there could have been some communication breakdowns between school insiders (teachers, staff, and administrators) and outsiders. Another explanation for this phenomenon could be that a group of the most influential people had emerged in the team, and people naturally wanted to communicate with the most influential people. These discoveries shed light on developing the interview protocol for the later stage of the study, and the underlying reasons are explained in the later section.

For all the respondents who did reply that there were certain people with whom they would like to talk about LT issues, most of them only met each other once or twice a month, with only a few exceptions for some teachers, but most teachers were in different schools, so they could not see each other very often. 
According to the answers respondents gave to the survey, it was found that, in addition to formal relationships that developed based on working relations among the team members, informal relationships did emerge within the group. Nine out of 12 respondents chose some team members as their vacation partners. However, three of them refused to choose anyone as a vacation partner because they didn't know anyone well enough. The reasons people chose others as vacation partners included: same hobbies and interests, sense of humor, same age, fascinating personalities, and know them longest. Furthermore, the partners chosen were always within their own stakeholder groups, which means that teachers chose teachers and administrators chose administrators, and people working in school never chose community members.

\section{Leadership and Communication Skills Admired}

According to the answers to the survey, four people from the administration group and two from the teacher group were chosen as team leaders, for they possessed certain leadership and communication skills desired by other members. These skills are summarized below.

- Stays on top of the issues

- Would do their share and designate out some responsibilities

- Works in a professional and respectful manner

- Will not sugar coat information

- Accepts the ideas of others

- Understands my job

- Thorough

- Efficient

- Creative

- Hard working

- High work ethic

- Has access to many resources

- Passion for students and learning

- Makes a person feel needed and appreciated

- Organization skills

- Knowledge of district

- Not afraid to do work themselves

- Out of the box thinking

- Keeps the team focused

- Not hesitant to speak

- Does not beat around the bush

\section{Team Members' Values, Beliefs, and Perceptions on Team Communication}

Interviewees were asked about the leadership role and whether the team vision, mission, and products to examine had been effectively communicated to the members. Most of the interviewees agreed that the LT provided them with a framework and a bigger picture of where the district needed to go. It helped them look at a more global picture of all the stakeholders 
involved in the reinvention process and helped them come to know different perspectives from stakeholders. Although not every member was clear about the vision, mission, and products of the LT, the members who provided answers agreed that the mission of the LT was to assist the rest of the school system with guidelines to improve schools. In addition, they were also aware that the mission of the LT might change over time. As one member stated:

Early on when we were doing vision-mission-beliefs, that was our mission. I think we really understood that to be our mission, but in essence, it probably wasn't our true mission; our true mission was to improve our schools and to guide this process. (From a community member, individual interview)

Compared with the vision and mission of the LT, the members' opinions on its products varied from person to person. The vision and mission statement was considered a major product of the team. Some considered that the major product was sharing ideas and getting feedback from different stakeholders, and some believed the products of the LT were the tools or guidelines that support the schools to form their teams and drive their reinvention processes. The inability to state the vision and mission of the LT and the mixed understanding of its products reflect that these concepts were not effectively communicated to the members, which was again confirmed by the answers given by some interviewees. Two members emphasized that the vision and mission of the LT was really cloudy at one point. As one member put it:

I don't think we quite understood our purpose. I think we were just doing what came upon us, but I don't think we really had a clear mission, and don't think we quite understood it. I'm sure we have one, but I didn't think we understood, and without that mission in our sights, I think we were just stagnant for a while. (From a community member, individual interview)

However, both of them also pointed out that the goal of the team had been defined in recent months and the team had been back on the right track. That largely was due to stronger leadership from the central office, which worked hard to reenergize, refocus, and redirect the team. One member stated that:

It's been a long journey, and it's a process. I think early on maybe we had another mission. Maybe our mission was to create a mission. Now the mission is there. We had to have a new goal of changing our schools, even though that was the original mission in essence. (From a teacher, individual interview)

Other members expressed the opinion that the LT had had thorough conversations and follow-up concerning its vision, mission and products. The seeming ineffectiveness might have been caused by some individuals not taking an active role or by gaps due to absences from the meetings.

In order to examine if the team had effectively communicated among its members about their particular roles in the team, participants were asked about this. Almost every member interviewed was clear about her or his particular role in the team, at least conceptually, since some community members were not very positive as to whether they had met the requirements of their roles. Generally speaking, the participants thought that they were expected to actively participate in the 
meetings, bring in their ideas and thoughts, and share their points of view with each other. They were specifically clear about their bridging role to communicate between the LT and their own stakeholder groups, although this clarification was reinforced only six months earlier, which is consistent with the time that talking points were sent out through e-mail to each member. This demonstrates that the team had been making efforts to emphasize the importance of communicating with all stakeholder groups.

It is worth noting that the teachers interviewed universally considered themselves as integral parts of the reinvention process and had high demands on themselves in terms of changing mental models, communicating within the team, learning related knowledge, and being supportive in their own buildings to move the reinvention process forward. Some mentioned that they attended administration courses or went to retreats. By comparison, although community members were clear that each was expected to bring an outsider perspective, they stated their concerns that sometimes they felt lost and didn't really know whether or not they were making contributions to the team. The interviewer further explored this issue and examined the reasons by asking questions related to these communication deficiencies.

As most of the members thought one of their roles was to communicate ideas back to their stakeholder groups, specific questions were asked to examine how this was accomplished. More than four participants stated that they found that the talking points sent out by the central office were helpful in this regard, and one principal said that he printed the notes together with their school's calendar, and most of his teachers liked it.

I put a two-week calendar on the back. They all like to hang it up in their rooms to see all the different things coming up in different days. But sometimes I just put the notes there. Sometimes I send them out, but you don't $k$ now whether they read them or don't read them. That's why I always print out a weekly insider and put [copies] in their mailboxes, because they at least pick them up to see the two-week calendar on the back. They like to see what's going on. (From a principal, individual interview)

Among community members, there was a consensus that it was tough to spread the word back to the community, partly because finding an appropriate arena was difficult. One of them offered the following comment.

That's the toughest thing. We have community meetings and we can't get them to show up, so we've got a mission to spread. We spread all the information and make people show up so we could tell them. That's one of the hardest things. The elementary [school] that had a movie for the kids and dinner for everybody, that was the one everybody came to. So they came for the food. And once they ate, they let the kids go to the movie and we talked about the Leadership Team. I think so much happens in everybody's life, and parents just think OK, you are doing OK, just do whatever you are doing. And they just don't have time to get involved - don't want to get involved. So spreading the word is hard. (From a community member, individual interview) 
Participants acknowledged that communicating back to their stakeholder groups was not effectively done, especially to community members, but they all realized the significance of involving most stakeholders, having them develop ownership, and bring in their outsider perspectives.

I do think these other stakeholders can bring perspectives. You know, all teachers, they think in a certain way. And when I was teaching, I found some of my best educational ideas from going to business seminars with my husband. It is a different mindset, but it applies. (From a community member, individual interview)

The interviewees analyzed some of the reasons behind the difficulty of reaching stakeholders. People who don't have kids or grandchildren in the system find it ideologically interesting, but it's difficult for them to feel as concrete about it. Despite the difficulty, this member believed that the effort of reaching stakeholder groups should be made persistently.

I think some of the meetings they had around the school with parents ... I went to one of them, just to see. It was well attended, had people who went away saying, "Well, I don't really understand all this." But unfortunately, you have to keep doing it, and redoing it, and redoing it. It's like making a sales call. You have to make seven to 10 exposures to get one solid response. That's been proved in business. I don't think it's any different in ideas. Parents are the ones who really need to be in this, and the opportunity for communicating with the STAR [students, teacher, and relationships] is great. Again, that means outside of the classroom, a teacher has to spend a lot of time and effort. (From a community member, individual interview)

Most of the participants thought they were supported by the team to play their roles, although one member did express his hope for more technology support from the team so that his building could be better equipped with facilities to serve the kids. All participants agreed that everybody on the team had equal opportunity to speak. They stated that it may have taken some time at the beginning to adjust to the group environment, but everyone was welcomed to speak up. This had been particularly effective when people were split into smaller groups. At the same time, they also realized that, due to personality and other reasons, it is not easy to get everybody to talk in the bigger group. As one of them put it:

Here again is the personality thing - that there might be some people, like I said, early on. I probably did not. That doesn't bother me now. If I have something I want to say, I will just say it out loud, put it in there. I can't picture anybody right now that I know who sits there and doesn't speak, but there is probably somebody that doesn't speak, at least as much. But do we value that anything less? No. We want everybody to speak up. (From a community member, individual interview)

\section{Sources and Channels of Communication}

For the sources and channels of communication within the LT, all the members interviewed shared the opinion that key people on the team, especially those on the Worker Bee team, served as 
communication sources. In addition, a new communication strategy, which had only been adopted six months earlier, had proved very effective. That is the central office staff summarized the "talking points" from each meeting and sent them to all members via email. According to them, the talking points had been useful because they served as a good reminder of what they did in each meeting and provided a good way for them to share what they had done in the LT with their stakeholder groups. Those talking points were produced specifically for the members to take back to their own stakeholder group members.

It needs to be noted that, although every participant was notified before the interview that the study was examining the internal communications within the LT, almost every participant touched on issues of external communication between the team and other stakeholder groups and provided suggestions. That feedback, although not the initial focus of the study, was good to have in that the issue of communication with other stakeholder groups was consistent with the participants' understanding of the LT role and the composition of the team itself.

\section{Communication Deficiencies}

The lack of informal communication was mentioned by every member interviewed as one of the communication deficiencies on the team. It is also consistent with the survey results presented above. As introduced by the members above, the LT meeting itself served as the primary venue for communication. However, the meeting was only held once a month; therefore most members interviewed felt there was a lack of understanding of people on a personal basis. Some of them didn't even know who some team members were and what they did. This issue was more obvious with community members, because most of them were not directly involved in the schools and had fewer opportunities to meet with other community members.

I don't know everybody who is on the Leadership Team very well. We only meet once a month. If everybody can have a chance that we do to sit down, and you don't have a genuine conversation about hey, who are you and what are you doing, how are things going. It's more of hey, let's discuss this. You just get to know their ideas. So I don't know people that well on the Leadership Team, and whether it's fortunate or unfortunate, our paths do not cross other than on the Leadership Team. (From a community member, focus group)

I only see people once a month for those meetings, whereas most people in this room see each other on a daily basis. People know each other on a personal basis. I'm very bad with names in some cases. I feel a little bit lost. There are only a handful of us who are not [working] there, and they don't have to remember too many people. (From a community member, focus group)

The members felt that there had been too many mental activities and idea-exchanges taking place, which had been effective to learn knowledge, but ineffective to get to know the members' needs. Though members were divided into small groups to work on certain activities almost every meeting, they didn't get the opportunity to work with every member and get to know them. As one of the members stated: 
When you do get into your groups, sometimes you will get into the ... I don't know if I've ever worked with one gentleman. What his business is about, I don't know. I've never worked with him yet. So I haven't worked with everyone in the Leadership Team. I don't know how we are grouped together. I don't know about those things. I don't ever see a list of who is on the Leadership Team and what they do. (From a community member, individual interview)

The lack of informal communication and less understanding of other team members contributed to a team culture that was more alien and intimidating for community members to the extent that several of them started to question their function and contribution to the team.

I never felt like my contributions are valued. I do leave often thinking, Gee, should I have said that? Have I gotten them off track of what they wanted to do? Am I raising an issue they've already talked about some other place but I didn't know that?" I do worry that maybe they have some agenda they are trying to move ahead with the larger group. And then I raised something that gets them off track. (From a community member, individual interview)

It has to be highlighted that all the community members interviewed felt uncomfortable offering their ideas and questioned their own value on the team, and they also analyzed various reasons behind that. In addition to the lack of informal interaction among team members and individuals' personality traits, they deemed the structure of the team ( 25 educators and four or five outsiders) and the jargon used by the team were primary impediments to communication among members of the LT. They thought the setting of mostly educators in the group not only was intimidating for people who were not so used to talking in front of big groups, but also got them stuck in a mode that they were just sitting there as advisory members watching internal people really doing the work.

\section{Management of LT Meetings}

All the participants provided positive feedback about the management of the LT meetings. The time of the meetings worked for everybody's schedule. Though the meetings were held monthly, most interviewees thought this frequency was enough because they understood that things needed time to develop. They also praised the organization of the meetings and activities. However, people also acknowledged that, since too many things were going on in each meeting, quite often they felt like they didn't quite understand the goals of each meeting and got nowhere in some of those meetings. One common opinion was that the agenda of each meeting was too packed.

The participants acknowledged the importance of the activities designed by the Worker Bee team for each meeting, and some of them were deemed very effective. For instance, several of the interviewees mentioned the activity in which they shared the Middle School redesign process. However, there were complaints that sometimes it seemed they were doing an activity that was 
well planned by the Worker Bees, but was not very relevant to the real world, or its purpose was not so clear, and they did not feel they could play an active role in it.

It seems that the minds are already made up. Or is that just something we do so we feel like we had some input for? You wondered if the products have been produced before you even started it. (From a principal, individual interview)

Sometimes it seems like we are doing all those mental exercises that don't get carried out in the real world. (From a principal, individual interview)

The participants also expressed mixed opinions on the leadership of the LT. On the one hand, some had seen the meetings as teacher-directed because the teachers usually facilitated and directed the activities. On the other hand, some stated the concern that they felt more like followers than leaders in the group because often the Worker Bee group planned all the activities. As one put it:

It's like we have a leadership team within the Leadership Team. (From a teacher, focus group)

This indicates that the LT had not encouraged the members to have input in planning the meetings or activities. Though time might be an issue with most of the members, being provided with some degree of decision making in the activities they will do in the meeting was not considered a bad thing.

The interviewees realized various problems with communication within the team and communications between the team and stakeholder groups. They detected communication deficiencies and raised suggestions. However, they unanimously acknowledged that solving communication problems was a long process, and they had already observed some positive change.

You have to spend money to make money; you have to spend time to save time with computers. At first it does not save time, and I think the same thing is true with the teachers. A man from St. Louis told us that the first year was hell, and the second year went much better, and it was 3-5 years out before they realized the benefits. I think that's one of the things we need to communicate to the community. They think, "Well, we got this new program, why isn't the world changed?" And it's not like that. You don't change your own life overnight, and you are not gonna move a school corporation over night. (From a teacher, focus group)

So even though the communication ... I don't think it's been what it could be, it has occurred. (From a community member, individual interview)

\section{Summary}

The following is a summary of the most important findings: 
Characteristics of the team communication

- Team members tended to choose others from the same stakeholder group as idea sharers.

- Formal relationships that developed were based on working relations among the team members.

- Informal relationships did emerge within the group.

Team members' values, beliefs, and perceptions about team communication

- The team had effectively communicated among its members about their particular roles in the team.

- The vision, mission, and products of the LT were not effectively communicated to the members.

- Most of the members thought one of their roles was to communicate ideas back to their stakeholder groups.

- Most of the members thought it was tough to spread the word back to the community, partly because finding an appropriate arena was difficult.

\section{Sources and channels of communication}

- The list of "talking points" had been useful because they served as a good reminder of what they did in each meeting and provided a good way for them to share what they had done in the LT with their stakeholder groups.

- The key people on the team, especially those on the Worker Bee team, served as main communication sources.

\section{Communication deficiencies}

- The team lacked informal communication.

- Sometimes, the activities for the meetings were not relevant to the real world and their purposes were not very clear.

- The team culture was more alien and intimidating for community members.

\section{Management of $L T$ meetings}

- The agenda of each meeting was too packed.

- The participants acknowledged the importance of the activities designed by the Worker Bee team for each meeting.

- Some activities were not relevant to the real world.

\section{Conclusions and Implications}

The descriptions from the interviewees reflect communication issues existing both within the team and between the team and other stakeholder groups. On the whole, the suggestions are helpful to address several of the 18 continuous processes in the SST Protocol, namely sustain motivation, develop and maintain appropriate leadership, develop group-process and teambuilding skills, establish team spirit, engage in reflection, communicate with stakeholders, and foster organizational learning. These suggestions will be discussed in relation to the research questions explored in the study and the implications for the SST Protocol. 


\section{Improve Communication Deficiencies and Communicate with Stakeholders}

One member suggested that assigning stakeholder jobs in the team might be a solution to bring in more parents or community members, which is also a good way to increase opportunities for meeting other members more informally. Another member suggested that, in order for people to have a better idea of how each member is communicating back to their stakeholder group, the LT should allocate special time for discussing this issue and make it transparent rather than continuing to keep it secretive. To help people know each other much better, they expressed a strong hope to allocate special time to dealing with members' questions and feedback, providing clarification if it's needed. A list with updated member information was highly welcomed. Moreover, the members expressed their willingness to see more mixed or shifted groups so that they would have the chance to meet and work with more members on the team. This is consistent with communicating with stakeholders, which is specified in the SST Protocol.

More representatives of stakeholder groups in the team would bring more perspectives into team discussion and activities and facilitate communication between the school and community. However, 40 people were already on the team, and the bigger a team gets, the harder it is for all to attend or to reach consensus. An alternative that has been included in the SST Protocol is to create "input groups" whereby each member of the LT facilitates a monthly meeting of people in their stakeholder group to share what the LT has talked about and get input for them to take back to the LT. The downside is that this doubles the time commitment of the LT member, but it gets much broader participation in the LT without increasing the size of the LT.

\section{Improve Communication Deficiency and Sustain Motivation of Community Members}

Sustaining motivation is one of the most important processes out of the 18 processes listed in the SST Protocol. To encourage community members to contribute to the team, the following solutions were suggested:

1. Be provided with a clearer understanding of the function of community members on the team and historically what contribution community members made to the team.

2. Visit schools and classrooms in order to have a better idea about what is going on in the school.

3. Recruit student members on the $L T$ to provide more concrete information to the community members.

4. Rather than sitting in a large group meeting, one-on-one or two-on-one meetings in informal surroundings (such as a coffee shop) might be more comfortable for most parents and community members.

5. The mentality needs to be changed from expecting people to come to school to going out and talking to families. 


\section{Improve Communication Channels and Sources, and Develop Group Process}

The participants identified various communication channels and sources that they thought might help address communication deficiencies within the team. These suggestions would likely improve group-process development in the LT and thereby improve group activities. For the problem of not remembering team members' names, one member suggested that the team keep a case of people's nametags so that each one can put it on during the meeting and return it afterwards. Another suggestion was to give each member a binder or a notebook and provide updated information about group members. Through the interviews, the researcher learned that there had been a binder for each member several years ago to keep related readings and information sheets. However, the binder got too heavy, and people just ceased bringing them to the meetings. An effective solution might be to keep the binder with limited pages, but no matter how the information would be stored, the members need to receive updated information on each member.

To facilitate communication both within the LT and with the outside stakeholder groups, it was suggested that a website could be built to provide podcasting and vodcasting of each LT meeting so that not only the team members, but everyone in the township could be able to know what is going on in those meetings. This would be a good way to spread the vision of the LT, keeping the teachers and community informed, and would act as a good way to introduce team members.

\section{LT Meeting Management and Fostering Team Learning}

Team learning within the LT has tremendous significance for the whole district, given the steering role it assumes. Several suggestions were made on the management of the meetings in order to foster team learning and for all the members to be clear about not only what they had done and what they needed to do in each meeting, but more importantly, what they had gained from what they had done and what they still felt fuzzy about and needed more clarification on.

1. Use dinnertime to have conversation, reviewing what they did last time and the agenda of the meeting for that day.

2. Pair the members with different people each dinnertime.

3. Allocate reflection time every meeting to give anyone who didn't speak the chance to speak up.

4. Assign one person in charge of the meeting each month. Let the members know who the go-to person will be if they have problems or questions. More consistency would be added to the meetings in this way.

5. It may take more than a meeting every month to make community members feel involved in the team. Therefore, aside from the LT meetings, three or four key members of the LT should go out to meet with community members and build stronger relationships with them.

6. If the LT decides the meeting frequency is not enough for the team, it was suggested to make each meeting longer rather than having another one each month. 
In order to give the LT a clearer sense of the value of each meeting activity, one implication the researchers got from the interviewees is that after each activity, the team should get members' feedback or at least provide them with an evaluation form, and then decide whether to keep the activity or not. A successful activity would be one that is relevant to educational issues, such as having discussions about how the high school work has informed the middle school work.

One of the implications for team-member recruiting is that the potential member should be someone who is proactive, aware of their role and driven to assume it, comfortable with largegroup discussion and willing to be integrated into the bigger group, and motivated to learn about different fields of knowledge. It's better if they have kids or someone who is involved in the school system.

\section{Limitations of the Study}

The limited number of respondents to the survey and limited number of members who accepted being interviewed greatly impact the credibility of the study results. Unwillingness to participate in the study was partly due to bad timing (the survey and interview were arranged between late November and early December, when most of the administrators and teachers were especially busy with their school work) and perhaps partly due to team members being reluctant to talk about or even to address communication issues they were having. Another possible reason is that they were just not interested in the research study itself.

To make the study complete and more valid, the researcher planned a second phase of data collection, and tried to arrange more interviews with the teachers and administrators, in order to depict a more thorough picture of communication within the LT. However, the second phase of interviews did not materialize due to the LT members' reluctance to accept interviews. A legitimate explanation for this could be that the LT members were too busy with their current professional roles to consider volunteering their time. Another explanation could be that the other LT members were not so aware of communication issues. It could be further explained that other team members, different than some community members and some teachers who accepted most interviews of the study, did not consider communication was a big issue for the team. Hopefully, more data could be gathered in the future to enrich the findings from the current study.

\section{Final Comments}

Communication is one of the most important factors that determine participants' contributions in any team effort, particularly an effort as complex as a district-wide systemic transformation process. The communication breakdowns that LT members experience could potentially deny the success of the effort. This research study addressed what those communication deficiencies were on one team at one point in time, and how to improve them. When members of a LT are not effectively communicating, opportunities to contribute, grow as a group, and continue the progress that the team is providing to the system-wide transformation are put at risk. Hence, 
studying and improving the communication of LT members is important to the successful implementation of a transformation effort in a school district.

For the eight participants who did accept to be interviewed, four of them were community members whose perspectives on communication problems in the LT were definitely different from those of members of other stakeholder groups. Therefore, more information needs to be collected from other stakeholder groups to verify the interpretation the researchers have so far.

The study also discovered some related research topics, such as how communication affects team members' performance, how the LT should improve its management for better communication to take place, and who should assume the leadership role within the LT. Therefore, this study should be considered a stepping stone in a long series of research studies to inform LTs and school districts about team membership interactions and communication.

\section{References}

Barrett, D. J. (2008). Leadership communication. New York: McGraw-Hill Companies.

Colletta, N. J., \& Perkins, G. (2007). Participation in the education and training sector. The World Bank Participation Sourcebook.

Comer, J. P., Haynes, N. M., Joyner, E. T., \& Ben-Avie, M. (1996). Rallying the whole village: the Comer process for reforming education. New York, NY: Teachers College Press.

Duffy, F. M., \& Reigeluth, C. M. (2008). The school system transformation (SST) protocol. Educational Technology, 48(4), 41-49.

Duffy, F. M., Rogerson, L. G., \& Blick, C. (2000). Redesigning America's schools: A systems approach to improvement. Norwood, MA: Christopher-Gordon.

Fiordo, R. A. (1990). Communication in Education. Calgary: Detselig Enterprises Ltd.

Jenlink, P.M., Reigeluth, C.M., Carr, A.A., \& Nelson, L.M. (1996). An expedition for change: Facilitating the systemic change process in school districts. Tech Trends, 41(1), 21-30.

Jenlink, P.M., Reigeluth, C.M., Carr, A.A., \& Nelson, L.M. (1998). Guidelines for facilitating systemic change in school districts. Systems Research and Behavioral Science, 15(3), 217233.

Joseph, R. (2003). Formative research on a design theory to facilitate systemic change in public school districts. Unpublished doctoral dissertation, Indiana University, Bloomington.

Mclntire, R. G., \& Fessenden, J. T. (1994). The self-directed school: Empowering the stakeholders. New York: Scholastic Inc.

Miles, M.B., \& Huberman, A.M. (1984). Analyzing qualitative data: A source book for new methods. Beverly Hills, CA: Sage Publications.

Pascoe, S. M. (2008). Factors influencing attendance for a leadership team in a school district. Unpublished doctoral dissertation, Indiana University, Bloomington. 
Reigeluth. C. M. (1997). Instructional theory, practitioner needs, and new directions: Some reflections. Educational Technology, 37(1), 42-47.

Reigeluth, C. M. (1999). Instructional-design theories and models. A new paradigm of instructional theory, Volume II. Mahwah, NJ: Lawrence Erlbaum.

Reigeluth, C. M. \& Frick, T. W. (1999). Formative research: A methodology for creating and improving design theories. In Reigeluth, C. M. Reigeluth (Ed.), Instructional-design theories and models. A new paradigm of instructional theory, Volume II. Mahwah, NJ: Lawrence Erlbaum.

Reigeluth, C. M. \& Joseph, R. (2001). The systemic change process. Facilitating systemic change [PowerPoint Presentation]. Department of Instructional Systems Technology, School of Education. Indiana University.

Schlechty, P. C. (1990). Schools for the 21st century. Leadership imperatives for educational reform. San Francisco, CA: Jossey-Bass.

Schlechty, P. C. (2002). Working on the work: An action plan for teachers, principals, and superintendents $\left(1^{\text {st }}\right.$ ed.). San Francisco: Jossey-Bass.

SDD - Social Development Department (1995). Technical note on enhancing stakeholder participation in aid activities. Overseas Development Administration.

Senge P. M. (1990). The fifth discipline: The art and practice of the learning organization. New York, NY: Doubleday Currency.

Sizer, T. R. (1984). Horace's compromise: The dilemma of the American high school. The first report from a study of high schools, cosponsored by the National Association of Secondary School Principals and the Commission on Educational Issues of the National Association of Independent Schools. Boston, MA: Houghton Mifflin.

Sizer, T. R. (2002). The Common Principles. Coalition of Essential Schools. http://www.essentialschools.org/pub/ces_docs/about/phil/10cps/10cps.html). CES National Website.

Slavin, R. E., \& Madden, N. A. (2001). Success for All: Research and reform in elementary education. Mahwah, NJ: Lawrence Erlbaum Associates.

Stringfield, S., Ross, S. M., \& Smith, L. (1996). Bold plans for school restructuring: The new American schools designs. Mahwah, NJ: Lawrence Erlbaum Associates.

Correspondence: Charles M. Reigeluth, Professor, Department of Instructional Systems

Technology, School of Education, Indiana University, Bloomington, Indiana, USA. 